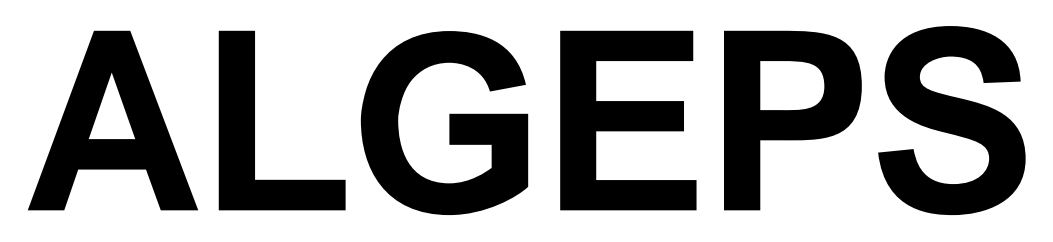

REVISTA DE GEOLOGIA, SĖRIE B no 639 - Juliol del 2013

ITINERARI GEOLÒGICO-MINERALÒGICO PER LES COMARQUES DE LA GARROTXA I D'OSONA: DES DE LES PRESES AL COLL DE BRACONS I AL SANTUARI DE BELLMUNT

Josep M. Mata-Perelló i Joaquim Sanz Balagué

Aquest recorregut va ésser experimentat amb docents el dia 15B DE GENER DEL 2012 


\section{ITINERARI GEOLÒGICO-MINERALÒGICO PER LES COMARQUES DE LA GARROTXA I D'OSONA: DES DE LES PRESES AL COLL DE BRACONS I AL SANTUARI DE BELLMUNT}

Per Josep M. Mata-Perelló i Joaquim Sanz Balagué

\section{ADVERTIMENTS}

Es tracta d'una sortida efectuada fa uns set anys, la qual ha estat modificada, amb la introducció de noves observacions. Tot i així, gaudeix del mateix fil conductor que va tenir aleshores.

Per d'altra banda, és una clàssica sortida geològica $i$ mineralògica, estructurada en una sèrie de PARADES o ESTACIONS. En cada una d'elles es faran les observacions geològiques i/o mineralògiques pertinents que s'escaiguin.

En qualsevol cas, cal tenir sempre una cura molt especial de respecte a la natura, al llarg de tot el recorregut; de l'itinerari.

\section{BREU INTODUCCIÓ}

La totalitat del recorregut d'aquest itinerari discorrerà exclusivament per una sola de les unitats geològiques que constitueixen el subsòl del nostre país, concretament per la Depressió Geològica de l'Ebre. Tot i així, s'iniciarà dintre dels sectors corresponents a la Serralada Transversal, per a finalitzar dintre del denominat Subpirineu. Així, al llarg de tot el recorregut s'aniran trobant exclusivament afloraments dels materials cenozoics que reblen l'esmentada depressió.

Malgrat que el recorregut de l'itinerari discorrerà exclusivament per la Depressió Geològica de l'Ebre, al llarg del recorregut, s'efectuaran reconeixements a distància de les altres dues unitats que constitueixen el subsòl de Catalunya: tant dels Pirineus (situats al Nord dels sectors per on discorrerà el recorregut) com dels Catalànids (ubicat al SE).

Per d'altra banda, el present recorregut transitarà per dues comarques. Així, śiniciarà a la comarca de la Garrotxa (integrant de les Terres de Girona), per a finalitzar dintre de la comarca d'Osona (situada dintre de la denominada Catalunya Central). 


\section{OBJECTIUS GENERALS}

A través d'aquest itinerari geològic-mineralògic, s'intentaran d'aconseguir els següents objectius:

1.- Observació de la Zona volcànica de la Garrotxa (inclosa a la Serralada Transversal Catalana), de les seves estructures i dels seus materials. Així, aquesta observació la podrem fer fonamentalment des del Mirador de Xenacs.

2.- Observació de la Serralada Transversal Catalana (part integrant de la Depressió Geològica de l’Ebre) i en concret del sectors corresponents al Cabrerès. Això ho podrem fer des de diversos indrets del recorregut; especialment entre Joanetes i el Coll de Bracons.

3.- Observació del Subpirineu (part integrant de la Depressió Geològica de $l^{\prime}$ Ebre). Això ho podrem fer des de diversos indrets del recorregut; especialment entre el Coll de Bracons i el Santuari de Bellmunt.

4.- Observació dels materials cenozoics que reblen la Depressió Geològica de l’Ebre (i tanmateix la Serralada Transversal Catalana i del Subpirineu), entre les Preses i el final del recorregut, al Santuari de Bellmunt. Aquests materials es distribueixen entre les següents unitats biostratigràfiques: Formació Armàncies, Formació Beuda (amb nivells de guixos blanc i grisosos), Formació Banyoles, Formació Coubet (amb conglomerats, gresos i calcàries), Formació Bracons, Formació Bellmunt, Formació Folgueroles (amb gresos i microconglomerats grisos), Unitat del Puigsacalm Superior (amb conglomerats, gresos i calcolutites grises) i Unitat Vidrà Inferior (amb gresos i calcolutites grises).

5,- Observació, a distància de les estructures de la Zona d'Apilaments Antiformes del Freser (del Sistema Pirinenc), que veurem al Nord del recorregut, des del Mirador de Xenacs, al principi del recorregut.

6.- Observació, a distància dels materials paleozoics (del Cambro-Ordovicià al Permià), que constitueixen la Zona d'Apilaments Antiformes del Freser.

7.- Observació, al llarg del recorregut dels diferents elements del Patrimoni Geològic i Miner, que es vagin trobant.

\section{ANTECEDENTS}

No tenim cap constància de l'existència de cap itinerari, que discorri íntegrament pels indrets on ho fa el present. Existeixen però, alguns antecedents com els següents: farem esment d’uns itineraris nostres, com: MATA-PERELLÓ (1995, 1996 1999, 2007a i 2007b). També farem esment del treball de GASSIOT i RIERA (1981).

Pel que fa a les característiques generals de la geologia regional, farem esment de dos treballs: GUIMERÀ et altri (1992), i RIBA et altri (1976). I, pel que fa a la geologia 
de la zona per la qual discorre el recorregut de l'itinerari, farem esment dels següents treballs: ARAÑA et altri (1983), IGME (1994a i 1994b), MALLARACH (1968) MALLARACH i RIERA (1981).

També, pel que fa a les mineralitzacions situades a les comarques per les quals discorre l'itinerari, farem esment d'un treball nostre; concretament de: MATAPERELLÓ (1991).

Tots aquests treballs figuren relacionats, per ordre alfabètic a l'apartat dedicat a la BIBLIOGRAFIA.

\section{RECORREGUT DE L'ITINERARI}

L'itinerari s'iniciarà al poble de les Preses, per tal de pujar fins al mirador de Xenacs, per on es farà una aturada. Després ens caldrà tornar a les Preses, per tal de continuar cap a Bas (tot anant per la carretera comarcal C - 63 (l'antiga C-152).

A continuació, 1'itinerari s'adreçarà cap el Coll de Bracons (seguint ara per la carretera C-37), i des d'aquí cap al Santuari de Bellmunt, per una carretera local. En arribar-hi es farà una nova aturada. Tanmateix es faran altres aturades al llarg d'aquest recorregut.

En aquest indret, finalitzarà el recorregut de 1'itinerari, ,olt prop del Santuari de Bellmunt.

\section{DESCRIPCIÓ DE L'ITINERARI}

Com ja es habitual, aquest itinerari s'estructurarà en una sèrie d'estacions (parades o aturades). En cada una d'aquestes parades es faran descripcions geològiques o mineralògiques, segons s'escaigui. En cada cas s'indicarà el número del mapa topogràfic a escala 1:50.000 on es troba l'indret.

En aquest cas, el recorregut de l'itinerari passarà per part dels dos següents fulls: 257 (dit d'Olot) i 294 (o de Manlleu). En tots els casos, aquests fulls són del IGC (Instituto de Geografia y de Cartografia de España).

Així doncs, la descripció de les diferents aturades que constitueixen el recorregut de l'itinerari, és la següent:

PARADA 1. MIRADOR DE XENACS (terme municipal de les Preses, comarca de la Garrotxa). (Full 295).

L'itinerari s'inicia a la sortida de la població de les Preses. A uns 500m, anant cap a Sant Esteve del Bas, es troba un camí (per la dreta de la carretera) que condueix 
cap al mirador de Xenacs. En un recorregut d'una mica més de $4 \mathrm{Km}$, per una pista en bon estat, s'arriba a l'Àrea de Xenacs. Després, per un sender ben senyalitzat, cal anar a peu fins al mirador.

Tot aquest recorregut, des de les Preses fins al mirador de Xenacs, es realitza entre els materials terciaris de l'Eocè, constituïts per nivells de gresos, margues i calcàries, els quals cabussen clarament cap a l'Oest. Aquests materials pertanyen als primers trams del recorregut a la Formació Puigsacalm; mentre que els trams més alts corresponen a la Formació Bellmunt, tot i que aquests ocupen una posició estratigràfica inferior en relació als anteriors.

Tanmateix, des d'aquest indret, es fa ben palesa la Serralada Transversal Catalana, amb el Puigsacalm; així com de diversos indrets del Sistema Pirinenc, fent-se palesos molts sectors de la seva Zona Axial, com el Canigó i el Costabona, entre altres indrets. Igualment es fan palesos molts sectors corresponents als Pirineus Meridional, com el Massís del Montgrí.

PARADA 2. ENTRADA A JOANETES, (Joanetes, terme de la Vall d'En Bas, comarca de la Garrotxa). (Full 294).

Després de realitzar la parada anterior, ens caldrà baixar de nou cap al poble de les Preses . En arribar-hi, ens caldrà seguir per la carretera C- 63 (l'antiga C - 152). Per aquesta carretera, es passarà per les Serres. Iniciant-se ací una fillola per tal d'arribar al veïnat de Joanetes (de la Vall d’En Bas), podem fer una nova aturada, després de recórrer uns $10 \mathrm{Km}$ des del Mirador de Xenacs.

Tot aquest recorregut, des de la parada anterior fins a l'indret de l'aturada, es van trobant afloraments dels materials terciaris de 1'Eocè, constituïts per nivells de gresos, margues i calcàries, els quals cabussen clarament cap a l’Oest.

Des d'aquest indret, tot mirant cap al NW es pot gaudir de l'interessant relleu del Puigsacalm, situat al Cabreres. Es situa entre afloraments cenozoics, els quals formen un interessants relieves en cuesta.

\section{PARADA 3. COLL DE BRACONS (termes de Sant Pere de Torelló i de la Vall d'en Bas, comarques d'Osona i de la Garrotxa). (Full 294).}

Després de la parada anterior, caldrà retornar cap al veïnat de les Serres, per tal d'agafar la carretera C - 37, la qual condueix cap el Coll de Bracons. A nosaltres ens caldrà fer una nova aturada, prop de la carretera vella (ja que la nova passa per un túnel). En arribar-hi, farem una nova aturada, a uns $6 \mathrm{Km}$ i escaig de l'anterior.

En aquest recorregut, haurem tornat a trobar afloraments dels materials geològics esmentats a les aturades anteriors. Aquests materials són eocènics i formen part de la Depressió Geològica de l'Ebre (que aquí també constitueix els relleus de la Serralada Transversal). 
Així, cap a la part alta, haurem trobat uns nivells de gresos i de margues grisblavoses, alternant amb gresos i margues rogenques, tot constituint en conjunt la Formació Bracons.

\section{PARADA 4. COLL DE L'HOSTAL DEL MAL GOVERN (terme municipal de Sant Pere de Torelló, comarca d'Osona). (Full 294).}

Després de la parada anterior, caldrà continuar cap a ponent per la carretera vella que es dirigeix cap a Torelló (inicialment la GIV-5273 i més tard la BV-52241, segons es circuli per les terres de Girona o les de Barcelona). En aquest recorregut es passarà molt aviat pel Veünat de les Cases de Bracons i posteriorment pel Veïnat de la Vola i posteriorment s'arribarà a Sant Pere de Torelló. Des d'aquí caldrà seguir per la carretereta que es dirigeix cap el Santuari de Bellmunt, però en arribar a 1'Hostal del Mal Govern ens caldrà fer una nova aturada. Així, haurem recorregut uns $20 \mathrm{Km}$ més, des de l'anterior. També cal dir que en aquest recorregut hem passat de la Garrotxa a la comarca d'Osona, on som ara.

La totalitat d'aquest recorregut, 1'haurem fet entre afloraments dels materials cenozoics que reblen la Depressió Geològica de l'Ebre per aquests sectors, que corresponen al Subpirineu i també a la Serralada Transversal Catalana (el més orientals i propers al Coll de Bracons).

Així, en un principi, s'hauran tallat els nivells de gresos i de margues grisblavoses, alternant amb gresos i margues rogenques, tot constituint en conjunt la Formació Bracons. Després, des de les Cases de Bracons fins a les immediacions de l'antic Km 22'6 es tallen els nivells rogencs de la Formació Bellmunt, amb gresos i calcolutites. Més enllà, fins arribar al proper Km 22’3 es tallaran els nivells de la Sotsunitat del Puigsacalm Inferior. Posteriorment, en el descens cap a Sant Pere de Torelló, es tallaran els nivells de la Sots-unitat del Puigsacalm Mig, fins arribar al Veïnat de la Vola de Dalt (prop del Km 21 de la vella carretera). I finalment, entre aquest indret i el poble de Sant Pere de Torelló, es tallaran els nivells de la Sots-unitat del Puigsacalm Superior; es a dir: en aquest tram hem descendit topogràficament, però hem anat ascendint estratigràficament, dintre de la sèrie de la Unitat Puigsacalm.

Tot i així, en anar ara des de Sant Pere de Torelló cap a l'indret de l'aturada es comencen a trobar inicialment els materials gris-blavosos de les calcolutites i gresos de la Sots-unitat del Puigsacalm Superior, que afloren prop del poble; però quasi immediatament, es troben de nou nivells de llims molt sorrencs de color gris blavós, que pertanyen a la Sots-unitat Puigsacalm Mig. Finalment, cap els voltants de la Masia de la Redortra, hi afloren els gresos gris-blavosos, alternant amb capes de calcolutites, que ja pertanyen a la Sots-unitat Puigsacalm Inferior. Aquest mateixos materials són els que trobem al Coll de 1'Hostal del Mal Govern. Es adir: en aquest recorregut des de Sant Pere de Torelló fins a l'indret de l'aturada, hem tornat a trobar els materials que ja hem vist des del Coll de Bracons fins a Sant Pere de Torelló, però ara en sentit invers.

Per d'altra banda, s'ha passat d'un cabussament gairebé horitzontal (entre Manlleu i poc després de Sant Pere de Torelló), a un cabussament inclinat cap a sud, que és el que correspon als materials que es troben prop de la present parada, de prop de 25 graus. FOTOGRAFIA 1. 


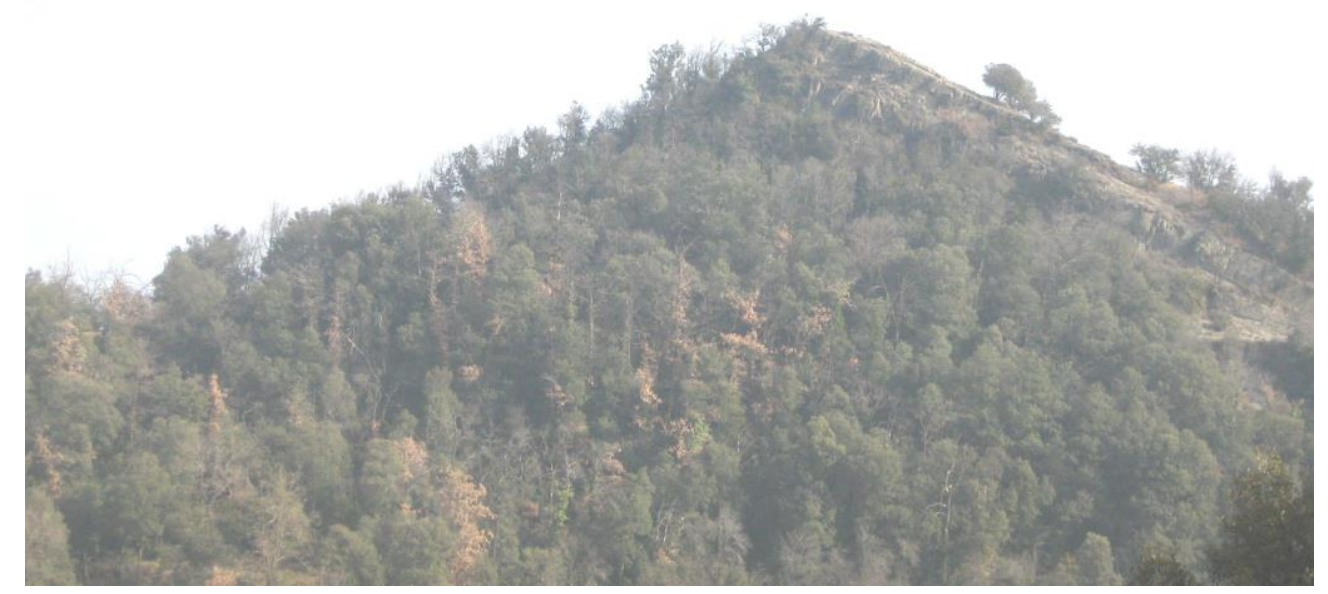

FOTOGRAFIA 1. Aspecte del cabussament cap al Sud, a migjorn del Santuari de Bellmunt

Tanmateix, mirant des d'aquest indret cap amunt, es pot veure que els materials es van verticalitzant cap al Nord, a mida que ens anem apropant cap al Santuari de Bellmunt. FOTOGRAFIA 2.

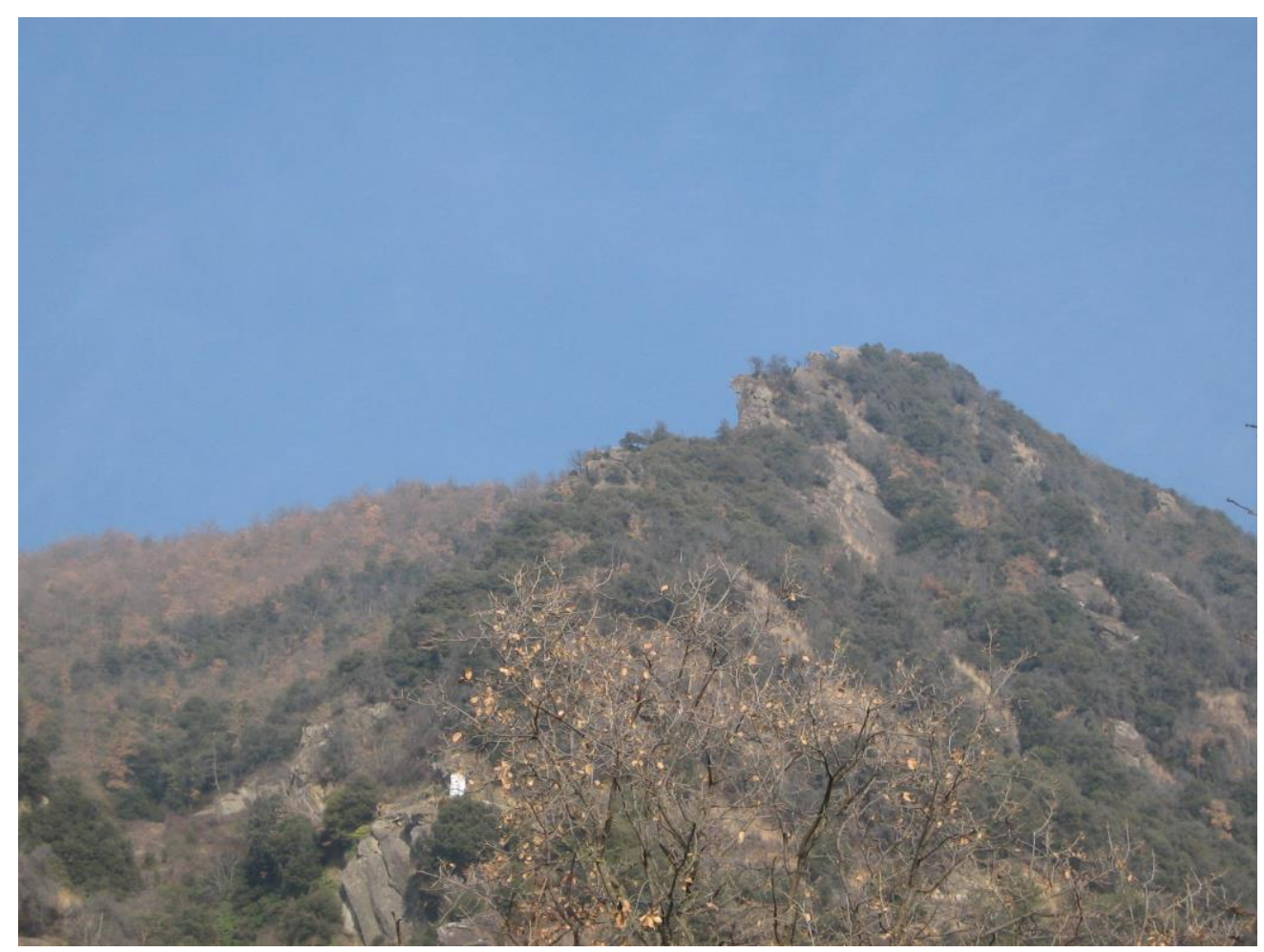

FOTOGRAFIA 2. Materials verticalitzats, prop del Santuari 
PARADA 5. FONT DE LA VIDRANESA, (terme municipal de Sant Pere de Torelló, comarca d'Osona). (Full 294).

Des de la parada anterior, caldrà continuar cap al Santuari de Bellmunt; així, es passarà primer pel Mirador del Pedronet de Montserrat; i després per la Font Vidranesa, on caldrà efectuar la present parada. Així, des de la parada anterior, caldrà fer un recorregut aproximat de poc més de $2,5 \mathrm{Km}$ per tal d'arribar fins a aquest lloc, on es farà la quarta parada.

En principi, en aquest recorregut s'han anat tallant els materials abans esmentats a la parada anterior. Tot i així, prop del Pedronet de Montserrat, adquireixen un caràcter detrític, cada cop més marcat.

Per d'altra banda el seu cabussament s'ha anat fent cada vegada més acusat, i arriba en aquest indret a ésser d'uns 65 graus, trobant-se els estrats inclinats cap al sud. Ara, en aquets darrers trams, s'han anat tallant uns nivells de gresos, que alternen amb conglomerats. Aquests materials, també pertanyen a la Sots-unitat Puigsacalm Inferior, i presenten un marcat color grisenc.

Per d'altra banda, al poc de passar la font, comença a trobar-se una alternança de gresos silícics de ciment carbonatat i de calcolutites rogenques. Aquests altres materials ja pertanyen a la Formació Bellmunt, i són inferiors als de la unitat acabada de veure.

Prop de l'esmentada Font de la Vidranesa, i tot continuant ascendint cap al Santuari de Bellmunt, es traspassa el nucli de l'Anticlinal de Bellmunt; i més enllà els estrats cabussen cap al nord, amb una forta inclinació propera als 70 graus.

Aquest anticlinal, constitueix l'estructura més septentrional de l'Avant-país de la Depressió Geològica de l'Ebre, i la més propera a l'Encavalcament de Vallfogona. Es tracta de un clar exponent de la component septentrional (la Pirinenca) d'aquestes estructures. Tanmateix, com a conseqüència d'aquestes estructures, l'eix de l'anticlinal no coincideix amb el de la serra, presentant-se al sud de la mateixa.

Per últim, cal dir que aquest anticlinal, del qual acabem de parlar, presenta un clar arrumbament de direcció Est-Oest.

\section{PARADA 6. SANTUARI DE BELLMUNT, (terme municipal de Sant Pere de Torelló, comarca d'Osona). (Full 294).}

Des de la parada anterior, cal continuar pel camí cap al proper Santuari de Bellmunt. En un principi s'arribarà a l'aparcament del final del tram transitable del camí. I, després caldrà ascendir a peu cap al santuari esmentat, que es troba al punt més alt del recorregut de l'itinerari, a $1.247 \mathrm{~m}$. S'hi arriba fent un recorregut d'uns $250 \mathrm{~m}$, des del paratge de la Font de la Vidranesa.

Des de la parada anterior, es pot veure com ha variat el cabussament dels materials, en haver passat al flanc septentrional de l'anticlinal esmentat anteriorment. Per d'altra banda, dalt del Santuari de Bellmunt, es tornen a trobar els nivells de gresos 
(alternants amb conglomerats), que pertanyen a la Sots-unitat del Puigsacalm Inferior. Com ja hem dit, aquests materials formen part del flanc septentrional de 1'Anticlinal de Bellmunt, i ja els havíem trobat en el recorregut anterior, abans d'arribar a la Font de la Vidranesa, a la parada anterior.

En aquest indret, es pot gaudir d'un bon exemple de relleu invertit (o d'inversió de relleu), ja que el nucli de l'Anticlinal de Bellmunt es troba situat a una cota sensiblement inferior a la del Santuari de Bellmunt, on ara ens trobem, i que forma part del flanc meridional de l'anticlinal anteriorment esmentat. És a dir: es troben al nucli en una posició topogràficament inferior a la d'un dels flancs, al contrari de com hauria d'ésser. Aquesta situació es la típica d’un relleu invertit.

Tanmateix, mirant cap a llevant es pot veure aquesta estructura a la propera Serra de Milamy, amb l'anticlinal clarament desventrat i alhora asimètric per la component septentrional de les forces. FOTOGRAFIA 3.

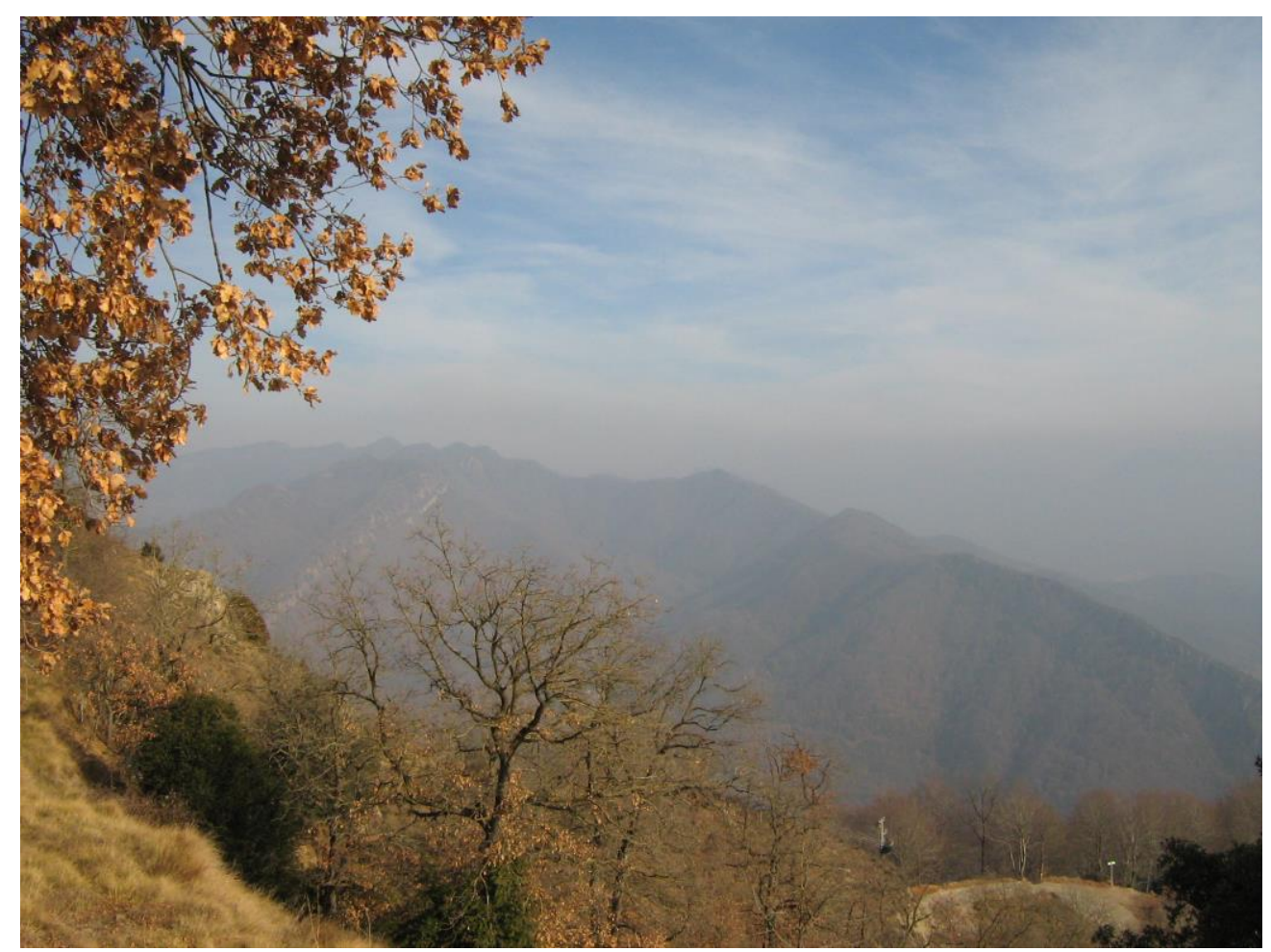

FOTOGRAFIA 3. Serra de Milany entre boirines, des del Santuari de Bellmunt. Anticlinal de Bellmunt

\section{EN AQUEST LLOC FINALITZA EL PRESENT ITINERARI.}




\section{BIBLIOGRAFIA}

ARAÑA, S. et altri (1983).- El volcanismo neógeno-cuaternario de Catalunya: caracteres estructurales, petrográficos y geodinámicos. Acta Geológica Hispánica, 18 (1), pp. 1-17, Barcelona.

GASSIOT, X. i RIERA, M. (1981).- Itinerari per la Zona Volcànica de Catalunya. Pub. $I C E-U A B, 36$ pàgines. Barcelona.

GUIMERÀ, J. et altri (1992).- Geologia (II), Història Natural dels Països Catalans, Vol. 2, 547 pag. Enciclopèdia catalana, S.A., Barcelona.

IGME (1994a).- Mapa Geológico de España a escala 1:50.000, Segunda série, Primera edición. Hoja y memória $n^{\circ} 256$ (Ripoll). Ins. Geominero y Tecnológico de España. Ministerio de Indústria y Energia. Madrid.

IGME (1994b).- Mapa Geológico de España a escala 1:50.000, Segunda série, Primera edición. Hoja y memória $\mathrm{n}^{\circ} 257$ (Olot). Ins. Geominero y Tecnológico de España. Ministerio de Indústria y Energia. Madrid.

MALLARACH, J. M. (1968).- Carta Geològica de la Regió Volcànica d’Olot. Edit.. Ajuntament d'Olot. Olot.

MALLARACH, J.M. i RIERA, M, (1981).- Els volcans olotins i el seu paisatge. Edit. Serpa. Barcelona.

MATA-PERELLÓ, J.M. (1991).- Els Minerals de Catalunya. Arxius de la Secció de Ciències, t. XCIII. Institut d'Estudis Catalans. Barcelona.

MATA-PERELLÓ, J.M. (1995).- Itinerari geológico - mineralògic per les comarques d'Osona i de la Garrotxa: des de Taradell a Torelló, Bellmunt i al Coll de Bracons. Inèdit. 10 pàgines. Manresa

MATA-PERELLÓ, J.M. (1996).- Apunts per a un itinerari geològico - mineralògic per les comarques del Ripollès i de la Garrotxa: des de Campdevànol a Santa Pau, i a Sant Joan de les Fonts. Inèdit. 10 pàgines. Manresa

MATA-PERELLÓ, J.M. (1999).- Itinerari geològic - mineralògic per les comarques de la Garrotxa i de la Selva: des de les Preses a Sant Julià del Llor. Inèdit. 10 pàgines. Manresa

MATA-PERELLÓ, J.M. (2007a).- Recorregut de recerca geològica i mineralògica per la comarca d’Osona: des de Tona a Taradell, Sant Sadurní d’Osormort, Torelló, Bellmunt i al Coll de Bracons. Inèdit. 14 pàgines. Manresa

MATA-PERELLÓ, J.M. (2007b).- Recorregut geològic i miner per les comarques de la Garrotxa i del Ripollès: des del Coll de Bracons a les Preses, Olot i a Sant Joan de les Abadesses. Inèdit. 10 pàgines. Manresa 
RIBA ARDERIU, O. Et altri. (1976).- Geografia Física dels Països Catalans. Edit Ketres. Barcelona. 